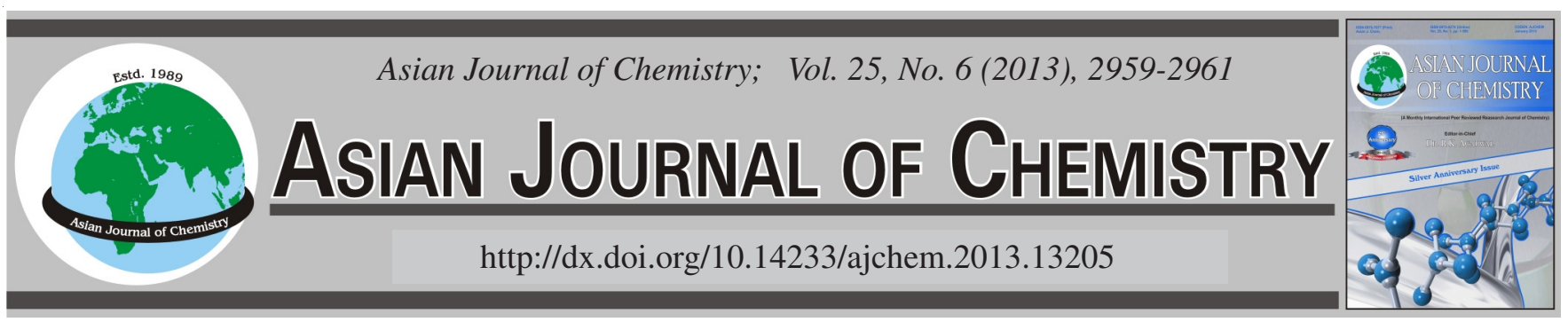

\title{
Determination of Arsenic in Panax notoginseng by Hydride Generation Atomic Fluorescence Spectrometry
}

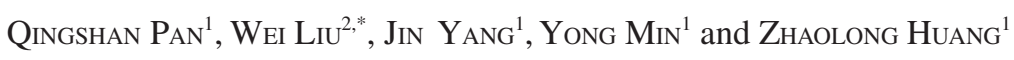

${ }^{1}$ Honghe University, Mengzi 661100, Yunnan Province, P.R. China

${ }^{2}$ Key Loboratory of Natural Pharmaceutical \& Chemical Biology of Yunnan Province, Yunnan 661100, P.R. China

*Corresponding author: E-mail: pqs1983@foxmail.com

(Received: 8 December 2011;

Accepted: 3 December 2012)

AJC-12496

To determine the total arsenic in Panax notoginseng a hydride generation atomic fluorescence spectrometry method was developed by atomic fluorescence spectrometry (AFS-3100). The samples were pretreated by high pressure digest. The experimental conditions were studied and optimized. There was a good linear relationship between the fluorescence intensity and arsenic concentration in the range of $0-80 \mu \mathrm{g} \mathrm{L}^{-1}$ with a correlation coefficient of 0.9995 , while the detection limit was $0.036 \mu \mathrm{g} \mathrm{L}^{-1}$, a relative standard deviation of $1.7 \%$ arsenic in the samples was $0.391 \mu \mathrm{g} \mathrm{g}^{-1}$ and a recovery range of $90.7-103.5 \%$ was obtained.

Key Words: Arsenic, Panax notoginseng, Atomic fluorescence spectrometry.

\section{INTRODUCTION}

Heavy metal pollution made the metals exceeding of Chinese traditional herbs in China are more and more ${ }^{1,2}$, China has not yet established national standards in the detection of the amounts of heavy metals in Chinese traditional herbs ${ }^{3,4}$. In this paper a hydride-atomic fluorescence spectrometry method was developed for the determination of trace arsenic in Panax notoginseng by atomic fluorescence spectrometry. The total arsenic content in Panax notoginseng grown in Yunnan were determined.

\section{EXPERIMENTAL}

AFS3100 double channel atomic fluorescence spectrometer (KCHG), Encoding arsenic hollow cathode lamp (Beijing Nonferrous Metal Research Institute), OPTIPLEX 380 computer system (Dell), DHG-9140A Blast Oven (Shanghai Yi Heng scientific instrument), CP224C electronic balance (Ohaus Instrument, USA), High-pressure digestion tank (100 mL). Operating conditions of AFS3100 is as given in Table- 1 .

Arsenic standard stock solution: $100 \mathrm{mg} \mathrm{L}^{-1}$ (National Research Center of standard materials); nitric acid: $68 \%$; sulfuric acid: $98 \%$; hydrochloric acid: $99 \%$. The standard stock solution of arsenic was diluted step with step by $5 \%$ hydrochloric acid solution to $1 \mathrm{mg} \mathrm{L}^{-1}$ as the working solution, arsenic standard stock solution and working solution were placed in the refrigerator to save; pre-reducing agent:thiourea, ascorbic acid; reducing agent: $10 \mathrm{~g} \mathrm{~L}^{-1} \mathrm{KBH}_{4}-5 \mathrm{~g} \mathrm{~L}^{-1} \mathrm{NaOH}$
TABLE-1

OPTIMAL OPERATING CONDITION OF AFS3100 INSTRUMENT

\begin{tabular}{|c|c|c|c|}
\hline Name & Parameter & Name & Parameter \\
\hline Element lamp & As & Measure method & Std. curve \\
\hline Wavelength (nm) & 197.3 & Reading mode & Peak area \\
\hline $\begin{array}{l}\text { Atomic-device } \\
\text { heightmm }\end{array}$ & 8 & $\begin{array}{l}\text { Carry gas flow rate } \\
\left(\mathrm{mL} \min ^{-1}\right)\end{array}$ & 500 \\
\hline -HV of PMT (V) & 250 & $\begin{array}{l}\text { Shielding gas flow } \\
\text { rate }\left(\mathrm{mL} \mathrm{min}^{-1}\right)\end{array}$ & 1000 \\
\hline Lamp current (mA) & 60 & Reading time (s) & 14 \\
\hline $\begin{array}{l}\text { Heat temperature } \\
\left({ }^{\circ} \mathrm{C}\right)\end{array}$ & 200 & Delaying time (s) & 1 \\
\hline
\end{tabular}

solution; carrier solution: $5 \%$ hydrochloric acid. All above reagents were guaranteed reagent. Water were deionized water.

Samples: Panax notoginseng grown in Yunnan were collected.

Sample treatment: The Panax notoginseng were washed with water and placed in blast oven dried at $80{ }^{\circ} \mathrm{C}$ for more than $12 \mathrm{~h}$, then smashed by the universal grinder, packed with a valve bag and placed in glass dryer. Weigh $0.5 \mathrm{~g}$ sample and then placed in a high-pressure digestion tank, adding $9 \mathrm{~mL}$ nitric acid, overnight; the next day, add $3 \mathrm{~mL}$ of hydrogen peroxide, tighten the digestion tank and placed in the oven, heating $4-5 \mathrm{~h}$ at the temperature of $150{ }^{\circ} \mathrm{C}$, then cooled to room temperature, removed the arsenic in the tank with $5 \%$ hydrochloric acid solution into $25 \mathrm{~mL}$ flask, deionized water to volume and do sample blank at the same time. 
Take arsenic standard working solution with $5 \%$ hydrochloric acid solution to prepare a series of arsenic standard solution with levels were $0,1,2,4,8$ and $10 \mu \mathrm{g} \mathrm{L}^{-1}$ and adding thiourea to content of $10 \mathrm{~g} \mathrm{~L}^{-1}$. Then set instrument operating conditions and measure the fluorescent intensity of the standard sample to obtain the standard curve and measure samples.

\section{RESULTS AND DISCUSSION}

Sample digesting conditions: In the experiment, different amount of reagents and digestion, digestion time and the influence of temperature on the digestion and determination were tested. The results showed that the fluorescent intensity of blank sample were very high with adding perchloric acid, sulfuric acid, it is not in favour of determination; mixed solution of nitric acid and hydrogen peroxide system is most suitable, when added $0.5 \mathrm{~g}$ sample, with the digesting time of $4-5 \mathrm{~h}$, temperature of $150{ }^{\circ} \mathrm{C}$; Digestion reagent nitric acid $9 \mathrm{~mL}$, hydrogen peroxide $3 \mathrm{~mL}$; get the most complete digestion, it is a colourless or slightly yellow solution.

Carry gas and Shielding gas flow rate: The carrier gas flow rate increased, would reduce the concentration of arsenic atoms, the intensity of fluorescence decreased; however, if the carrier gas flow rate were too small, it would affect the stability of argon flame. Experiment tested the fluorescent intensity of flow of 300-600 $\mathrm{mL} / \mathrm{min}$, when the carrier gas flow rate were $500 \mathrm{~mL} / \mathrm{min}$, the results were best. Shielding gas is to protect the internal reaction gas, too low shielding gas were difficult to stop the fluorescence quenching affected by the external gas, too much will dilute atomic vapor, reducing sensitivity. In this paper, the influence of the shielding gas to the intensity of fluorescence were tested at $800-1100 \mathrm{~mL} / \mathrm{min}$, the results show that it is best when the shielding gas at $1000 \mathrm{~mL} / \mathrm{min}$.

Selection of -HV of PMT and lamp current: When the negative high voltage of the photomultiplier tube were between 200-300 V, the standard series solution of arsenic were measured; the results showed that with the negative pressure increases, the instrument sensitivity increases, while the fluorescence values and standard curve linearity increased. When the negative high voltage of photomultiplier were too high, the noise increased with the increase of fluorescence, making the instrument unstable and the linearity drastically reduced; The ratio of signal to noise is more bigger, the sensitivity of the instrument is more higher. Therefore, when the sensitivity and the linear correlation meet the requirements, a lower negative high voltage of photomultiplier should be adopt. In this study, when the negative high voltage were $250 \mathrm{~V}$, the sensitivity and linearity were best. In a certain range, the intensity of fluorescence and sensitivity increased with the increasing of lamp current; but we must consider the noise, life of lamp and self-absorption phenomenon, the results were best when the lamp current of arsenic at $60 \mathrm{~mA}$.

Effect of the acidity of medium: In acid medium, trace of other heavy metals had a great influence on the fluorescent intensity of blank samples; in this study, hydrochloric acid, nitric acid, sulfuric acid was selected as the medium; the result showed that the hydrochloric acid have a lowest fluorescent intensity and best stability. Reaction of arsenic hydride have a wide range of acidity, in the experiment, the effect of the hydrochloric with 1-10\% concentration to the fluorescent intensity of arsenic at content of $2 \mu \mathrm{g} \mathrm{L}^{-1}$ were tested, the results show that when the concentration of the hydrochloric acid were in the area of 5-10\%, the fluorescent intensity of arsenic had a good stability. However, the greater the acidity grown, the bigger the value of the fluorescence of blank grown and the argon hydrogen flame increasing made the stability of the fluorescence decreased; therefore, the fluorescence of blank should as low as possible, but it should not too low, so as not to affect the efficiency of hydride reaction. So the acidity of medium was selected at $5 \%$.

Effect of the acidity of the liquid carrier: The acidity of liquid carrier would affect the fluorescent intensity of blank samples and the efficiency of hydrogenation. In the experiment the effect of the liquid carrier acidity with concentration of $1-10 \%$ to the fluorescent intensity of sample with $0.4 \mu \mathrm{g} \mathrm{L}^{-1}$ arsenic was tested, the results show that when the concentration of liquid carrier acidity were in the area of 3-6\%, the fluorescent intensity of arsenic were stable and higher, However, the greater the liquid carrier acidity grown, the bigger the value of the fluorescence of blank grown, the argon hydrogen flame grown also which made the stability of the fluorescence decreased; and the liquid carrier acidity should not too low so as not to affect the efficiency of hydride reaction. So the liquid carrier acidity was selected at $5 \%$.

Effect of the pre-reducing agent and time: The As(V) must be pre-reduced to As(III), to facilitate the hydrogenation reaction. The thiourea, thiourea-ascorbic acid $=1: 1$, ascorbic acid these three kinds of systems as pre-reduction agent were tested. The result shown the effect of thiourea with content of $10 \mathrm{~g} \mathrm{~L}^{-1}$ was best. And the effect of pre-reducing time with 5-120 min to the fluorescent intensity of sample with $2 \mu \mathrm{g} \mathrm{L}^{-1}$ arsenic was tested, the results show that when the pre-reducing time was in the area of 40-60 min, the effect was best.

Effect of the reducing agent: Reducing agent $\left(\mathrm{KBH}_{4}\right)$ mainly affects the efficiency of hydride generation and argon hydrogen flame. The higher concentration of reducing agent is conducive to the efficiency of hydrogenation, But the higher concentration of $\mathrm{KBH}_{4}$ generated too much hydrogen, which made the argon-hydrogen flame increased and the fluorescence weaken. In the experiment the effect of the $\mathrm{KBH}_{4}$ with concentration of $5-30 \mathrm{~g} \mathrm{~L}^{-1}$ to the fluorescent intensity of sample with $2 \mu \mathrm{g} \mathrm{L}^{-1}$ arsenic was tested, the results show that when the concentration of $\mathrm{KBH}_{4}$ were $20 \mathrm{~g} \mathrm{~L}^{-1}$, the fluorescent intensity of arsenic was stable and higher, So the concentration of $\mathrm{KBH}_{4}$ was selected at $10 \mathrm{~g} \mathrm{~L}^{-1}$.

Effects and elimination of interfering ions: The effects of 2000 times of $\mathrm{K}^{+}, \mathrm{Na}^{+}, \mathrm{Ca}^{2+}, \mathrm{Mg}^{2+} ; 2000$ times of $\mathrm{Fe}^{3+}, \mathrm{Zn}^{2+}$, $\mathrm{Cu}^{2+}, \mathrm{Co}^{3+}, \mathrm{Ni}^{2+} ; 200$ times of $\mathrm{Pb}^{2+} ; 100$ times of $\mathrm{Bi}^{3+}, 20$ times of $\mathrm{Sb}^{3+}, \mathrm{Hg}^{2+}$ to the determination of sample with $4 \mu \mathrm{g} \mathrm{\textrm {L } ^ { - 1 }}$ arsenic were tested. The result shown that with the $10 \mathrm{~g} \mathrm{~L}^{-1}$ thiourea, all above the existence of these multiple metal elements did not affect the determination of arsenic.

Linear range, detection limit and precision: The standard samples were tested at optimum conditions, the results showed that the working curve of arsenic had good linear coefficient in the range of $0-80 \mu \mathrm{g} \mathrm{L}^{-1}$, with a correlation coefficient of 0.9995. Continuous determination of the standard blank 
solution 11 times, according to the instrument detection limit $\mathrm{DL}=3 \sigma / \mathrm{K}(\sigma:$ the standard deviation of fluorescent intensity of blank sample solution, $\mathrm{K}$ : the slope of standard curve), while the detection limit was $0.036 \mu \mathrm{g} \mathrm{L}^{-1}$. The standard arsenic solution with a concentration of $0.6 \mu \mathrm{g} \mathrm{\textrm {L } ^ { - 1 }}$ was continuously measured for 11 times to calculate the relative standard deviation was $1.7 \%$.

Determination of samples and recovery: The results shown in Table-2.

TABLE-2

\begin{tabular}{lcccc}
\multicolumn{5}{c}{ TABLE-2 } \\
\multicolumn{5}{c}{$\begin{array}{c}\text { DETERMINATION OF TOTAL ARSENIC } \\
\text { IN SAMPLES AND RECOVERY }\end{array}$} \\
\hline \multicolumn{1}{c}{ Samples } & $\begin{array}{c}\text { Total arsenic } \\
\left(\mu \mathrm{g} \mathrm{g}^{-1}\right)\end{array}$ & $\begin{array}{c}\text { RSD } \\
(\%)\end{array}$ & $\begin{array}{c}\text { Added } \\
\left(\mu \mathrm{g} \mathrm{g}^{-1}\right)\end{array}$ & $\begin{array}{c}\text { Recovery } \\
(\%)\end{array}$ \\
\hline $\begin{array}{l}\text { Panax } \\
\text { notoginseng }\end{array}$ & 0.391 & 3.7 & $0.2 / 0.3 / 0.4 / 0.5$ & $90.7-103.5$ \\
\hline
\end{tabular}

\section{Conclusion}

This determination of total arsenic in the samples were higher than the standard of some foods ${ }^{5}$, the total arsenic in notoginseng was $0.391 \mu \mathrm{g} \mathrm{g}^{-1}$, which may be related to heavy metal pollution in the growing areas.

\section{ACKNOWLEDGEMENTS}

This work was support by Research of National Quality Inspection Standards of Nonprofit Industry in China (Subject: 200810998) and Honghe University (Subject: 10BSS133).

\section{REFERENCES}

1. E.S.J. Harris, S.G. Cao, B.A. Littlefield, J.A. Craycroft, R. Scholten, T. Kaptchuk, Y.L. Fu, W.Q. Wang, Y. Liu, H.B. Chen, Z.Z. Zhao, J. Clardy, A.D. Woolf and D.M. Eisenberg, Sci. Total Environ., 409, 4297 (2011).

2. S.Q. Chen and B. Chen, Procedia Environ. Sci., 5, 153 (2011).

3. U. Injang, P. Noyrod, W. Siangproh, W. Dungchai, S. Motomizu and O. Chailapakul, Anal. Chim. Acta, 668, 54 (2010).

4. A. Moutsatsou, E. Chalarakis and G. Zarangas, J. Hazard. Mater., 96, 53 (2003).

5. GB 2762-2005, The Tolerance Limit of Arsenic in Food. 